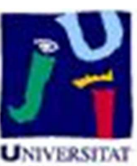

Título artículo / Títol article: LCC-HVDC Connection of Offshore Wind Farms With Reduced Filter Banks

Autores / Autors

R. Blasco-Gimenez, N. Aparicio, S. AñóVillalba, S. Bernal-Perez

Revista:

Industrial Electronics, IEEE Transactions on

Versión / Versió:

Versió post-print

Cita bibliográfica / Cita bibliogràfica (ISO 690):

BLASCO-GIMENEZ, Ramon, et al. LCCHVDC Connection of Offshore Wind Farms With Reduced Filter Banks. Industrial Electronics, IEEE Transactions on, 2013, vol. 60, no 6, p. 2372-2380.

url Repositori UJI: 


\title{
LCC-HVDC Connection of Off-shore Wind Farms with Reduced Filter Banks
}

\author{
R. Blasco-Gimenez, Senior Member, IEEE, N. Aparicio, Member, IEEE, S. Añó-Villalba, and S. Bernal-Perez
}

\begin{abstract}
Despite being more efficient, the LCC-HVDC links for the connection of large off-shore wind farms have the filter bank size as one of their main drawbacks. This paper shows how the HVDC rectifier filter banks can be substantially reduced by taking advantage of the additional control possibilities offered by the use of wind turbines with fully rated converters.

PSCAD simulations validate the operation of the wind farm and a diode rectifier HVDC link with a capacitor and filter bank five times smaller than its usual value. The proposed control algorithm allows for good harmonic and reactive power sharing between the different wind turbines.

As the reduced capacitor bank operation leads to a redistribution of harmonic and reactive currents, an efficiency study has been carried out to evaluate the new power loss distribution with the reduced filter banks.
\end{abstract}

Index Terms-HVDC transmission control, Wind power generation, Power generation control, Energy efficiency, Power system harmonics.

\section{INTRODUCTION}

W IND turbines equipped with fully rated converter is the favored technology for off-shore wind farms [1], [2]. They effectively contribute to voltage and frequency control of the off-shore ac-grid [3], [4]. It has been also shown that they can also perform the distributed control of all the duties usually carried out by a thyristor based HVDC rectifier [5]. So it permits the replacement of the thyristor rectifier by an uncontrolled diode based rectifier [3], [4].

The use of single generators connected to diode based HVDC rectifiers has important advantages, including smaller conduction losses, smaller installation cost and higher reliability with respect to thyristor based rectifiers [6]-[8]. Besides, existing distributed control techniques allow for joint operation of wind turbines and HVDC diode rectifier in a similar way as traditional thyristor rectifier HVDC links, i.e. HVDC rectifier voltage or current control mode of operation, VDCOL fault protection, etc. [3]. A similar solution consists on the series connection of individual wind-turbine rectifier modules at the expense of more stringent isolation requirements on the individual wind turbine transformers [9].

Manuscript received January 31, 2012. Accepted for publication October 11,2012 . The present work was supported by the Spanish Ministry of Science and Technology funds under Grant DPI2010-16714.

Copyright (C) 2012 IEEE. Personal use of this material is permitted. However, permission to use this material for any other purposes must be obtained from the IEEE by sending a request to pubs-permission@ieee.org.

R. Blasco-Gimenez, S. Añó-Villalba, and S. Bernal-Perez are with the Universitat Politècnica de València, 46022 València, Spain (e-mail: r.blasco@ieee.org, sanyo@die.upv.es, sbernal@die.upv.es).

N. Aparicio is with the Universitat Jaume I, 12071 Castelló de la Plana, Spain (e-mail: aparicio@uji.es).
However, in spite of the advantages of LCC-HVDC links in terms of efficiency and power carrying capability [10]-[12], they are not being used for the connection of off-shore wind farms, in favor of modular multilevel (MML) VSC-HVDC stations [13]-[15]. One of the main obstacles for the use of this, otherwise very successful technology, is the need of large and costly capacitor and filter banks [16]. Noticeably, the harmonics produced by the LCC converters are relatively large and require filtering [17]. Moreover, the amount of filtering required depends heavily on both the active power being transmitted by the HVDC link and the harmonic characteristics of the ac network. Therefore, filter design requires a detailed ac network analysis and represents one of the most difficult areas on the development of a LCC-HVDC link and subject of ongoing research [18].

Additionally, filter and capacitor banks provide the reactive power required by the rectifier and its transformer. Even when the rectifier is fired at zero degrees (uncontrolled rectifier), the current displacement caused by the commutation reactance and the leakage reactance of the rectifier transformer leads to a substantial amount of reactive power, typically in the range of 0.4-0.6 pu. Even in the case where CSC-HVDC converters are used, filters rated up to $0.24 \mathrm{pu}$ are required [19].

On-shore installations of the considered rating would use a typical of four to five capacitor and filter banks, each one taking an area between 400 to $1200 \mathrm{~m}^{2}$. Therefore, total filter area might be several times larger than the valve building itself. The proposed five-fold reduction on filter area is a clear advantage for off-shore applications.

The study in [4] introduced a distributed control strategy for the coordinated control of the wind power plant (WPP) and the HVDC link. However, it did assume the use of large capacitor and filter banks, which might be inadequate for offshore applications.

This paper shows that the aforementioned control strategy can be used with little modification with reduced rectifier capacitor and harmonic filter banks. Adequate operation has been shown when the capacitor and filter banks are reduced from 446 MVA (0.45 pu) to 89 MVA (0.09 pu).

As the harmonic filter reduction implies larger harmonic distortion, a detailed study on the harmonic contents on voltages and currents has been carried out. Moreover, the harmonic distortion analysis has been used to calculate the additional transformer and converter losses.

The effects on overall losses and equipment rating due to the additional reactive power from the wind power plant are also studied.

Therefore, this paper shows the suitability of the control 


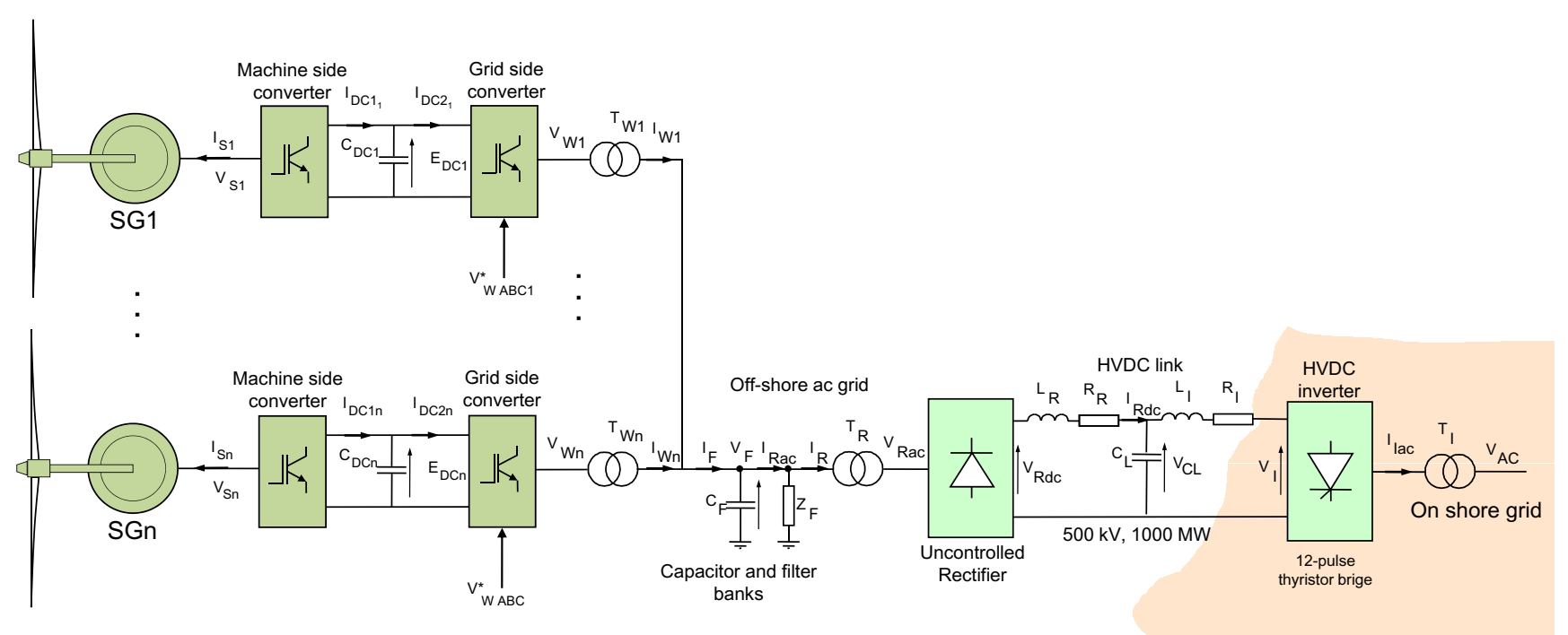

Fig. 1. SG-Based off-shore wind farm with HVDC connection

strategy proposed in [4] for operation with substantially reduced filters, together with a detailed study of its possible drawbacks.

\section{System Description}

The system under study is shown in Fig. 1. The wind farm consists on 200 wind turbines rated at $5 \mathrm{MW}$ each one, totaling $1 \mathrm{GW}$ aggregated power. The wind turbines are connected to the local off-shore grid using fully rated converters [20], [21]. The off-shore ac-grid is connected to the on-shore transmission grid using a 12-pulse diode rectifier HVDC link [3], [4].

Reactive power compensation and harmonic filtering is carried out by the capacitor and filter banks with parameters $C_{F}$ and $Z_{F}$ respectively. Their values are obtained from the CIGRE benchmark model [22] (scaled to the appropriate voltage level). The baseline case assumes that the capacitor and filter banks are rated a total of 446 MVA divided into four equal banks that would be switched on and off depending on the generated power. The parameters of the HVDC link have been also obtained from the CIGRE benchmark model. Finally, the wind farm has been modelled using a total of five aggregated wind turbine clusters of different rated power $\left(S_{R 1}=390 \mathrm{MVA}, S_{R 2}=300 \mathrm{MVA}, S_{R 3}=200 \mathrm{MVA}, S_{R 4}=\right.$ $100 \mathrm{MVA}$ and $\left.S_{R 5}=10 \mathrm{MVA}\right)$. The machine-side converter of each of the wind turbines is used to control the wind turbine dc-link voltage $E_{D C}$ [3], [23].

The HVDC link is modelled using a $T$-equivalent of the DC transmission line, whereas the on-shore inverter station is based on a standard twelve pulse thyristor bridge. The analysis of the off-shore ac grid has been carried out neglecting the line impedances and wind turbine transformer shunt impedances.

Therefore, the off-shore ac-grid dynamics in a synchronous frame rotating at $\omega_{F}$ and oriented on $V_{F}$, i.e. $V_{F q}=0$, can be written as [4]:

$$
\frac{d}{d t} V_{F d}=\frac{1}{C_{F}} \sum_{i=1}^{n} I_{W d i}-\frac{1}{C_{F}} I_{R a c d}
$$

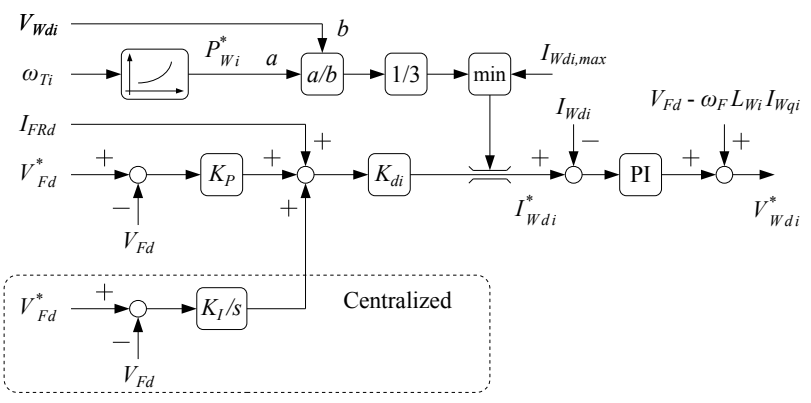

Fig. 2. Off-shore ac-grid voltage control.

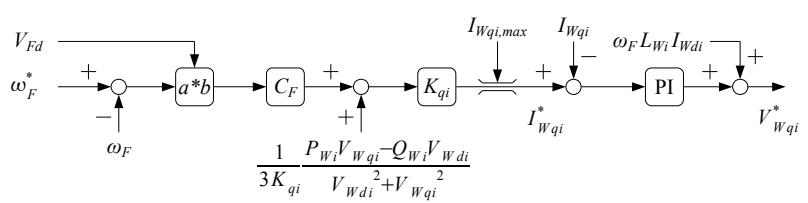

Fig. 3. Off-shore ac-grid frequency control.

$$
\omega_{F} V_{F d}=\frac{1}{C_{F}} \sum_{i=1}^{n} I_{W q i}-\frac{1}{C_{F}} I_{R a c q}
$$

The individual wind turbine d-q currents $\left(I_{W d i}\right.$ and $\left.I_{W q i}\right)$ can be controlled to follow desired step references with simple PI controllers.

\section{A. Off-shore ac-grid voltage and frequency control}

It is clear from (1) that the overall WPP active current $\left(I_{F d}^{*}=\sum_{i=1}^{n} I_{W d i}^{*}\right)$ can be used to control the off-shore acgrid voltage $V_{F d}$. Equation (2) can also be obtained from the reactive power balance of the off-shore grid. Assuming $V_{F d}$ is appropriately controlled, then the overall reactive current supplied by the wind farm $\left(I_{F q}^{*}=\sum_{i=1}^{n} I_{W q i}^{*}\right)$ can be used to control the off-shore grid frequency $\omega_{F}$. The WPP voltage and frequency control loops are shown in Figs. 2 and 3, respectively [4]. Note reactive power droop depends on 

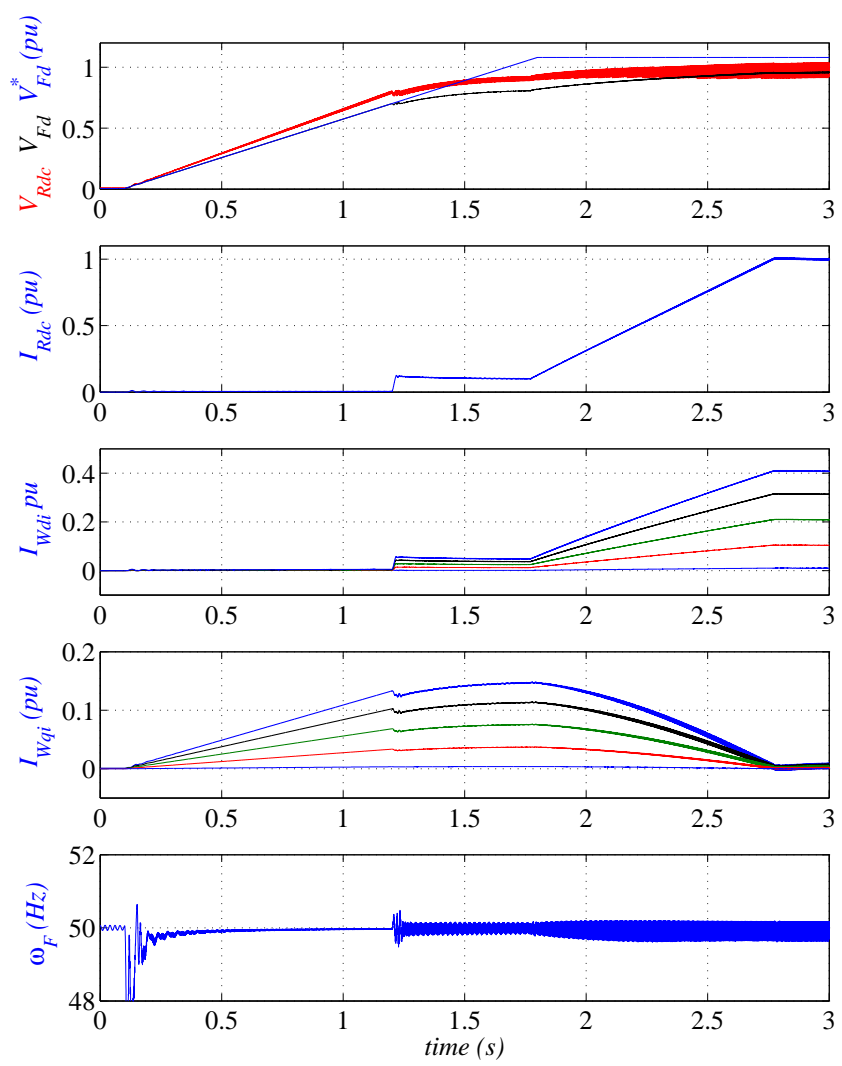

Fig. 4. Start-up operation with original capacitor and filter banks.

frequency measurement, so adequate sharing can be achieved with relative ease.

During normal operation, the HVDC diode rectifier acts as a voltage clamp on $V_{F d}$. Therefore, the different voltage control loops are saturated and inject a current determined by each wind turbine optimal characteristic [24].

On the other hand, if the distributed controller is no longer saturated, local voltage control will be carried out by the wind turbines. This is the case when the HVDC line is disconnected or when the inverter is operating in current control mode.

The voltage control loop is designed to have a $20 \mathrm{~Hz}$ closed loop bandwidth, therefore, communication delays on the centralized integrator in the range of $5-10 \mathrm{~ms}$ can be easily tolerated. A detailed description of the control strategy can be found in [4].

\section{Distributed Operation With Reduced Filter BANKS}

It has been previously shown that the proposed control strategy can successfully operate during the disconnection and subsequent reconnection of a large part of the capacitor and filter banks [4]. This result proves the robustness of the control system to changes in filter capacitance. Moreover, if the voltage and frequency controls are designed taking into account the value of the reduced filter banks, then it is possible to substantially reduce the reactive power rating of the capacitor and filter banks. Therefore, the capacitor and filter banks from the CIGRE benchmark model [22] have been
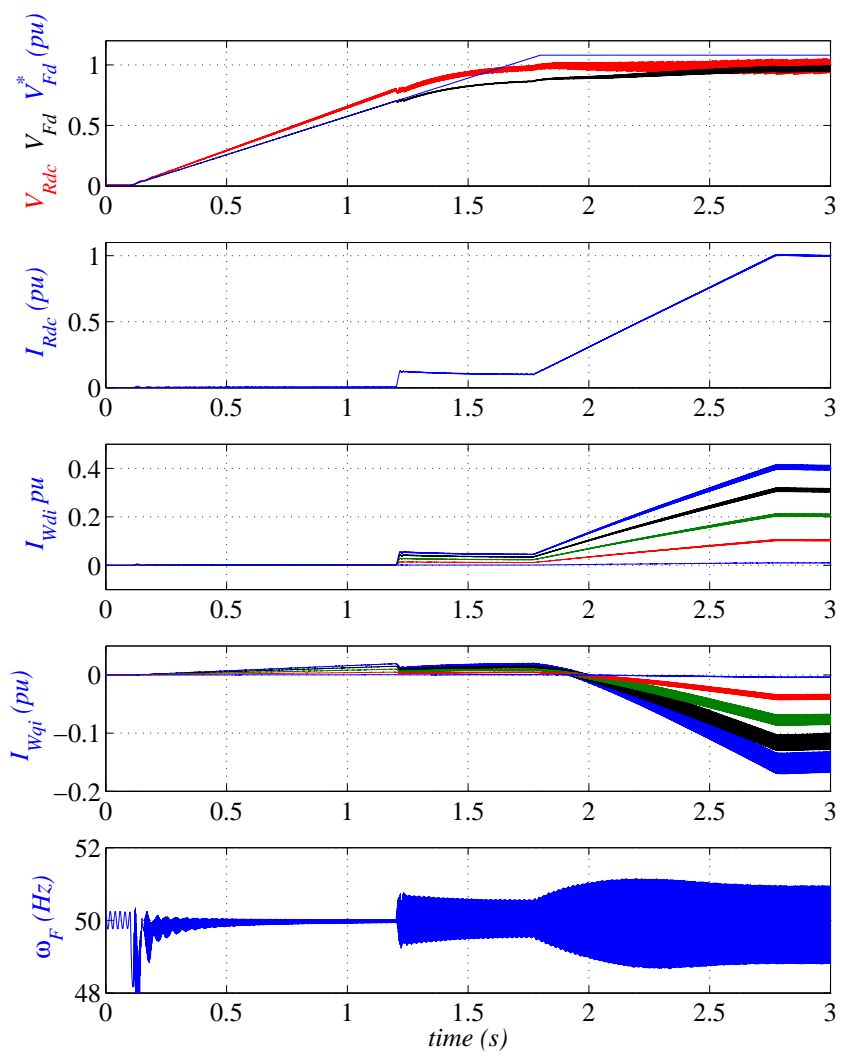

Fig. 5. Start-up operation with reduced capacitor and filter banks.

substituted by a single capacitor bank rated one fifth of the original capacitor and filter bank size.

The front-end converter current loop bandwidth has been designed to be around $180 \mathrm{~Hz}$, which corresponds to a switching frequency of $1 \mathrm{kHz}$. In this way, $11^{t h}, 13^{\text {th }}, 23^{\text {rd }}$ and $25^{\text {th }}$ harmonics are all above the bandwidth of the current loops.

Figs. 4 and 5 show the connection transient of the off-shore grid with original and reduced capacitor bank, respectively. Initially, the on-shore thyristor bridge is blocked and the offshore ac-grid voltage reference $\left(V_{F d}^{*}\right)$ is ramped up from 0 to $1.1 \mathrm{pu}$. When the HVDC link voltage $\left(V_{R d c}\right)$ reaches $0.75 \mathrm{pu}$ $(t=1.2 \mathrm{~s})$, the on-shore thyristor bridge is deblocked.

To ensure a smooth transition, both the wind farm power and the inverter current references are limited to $0.1 \mathrm{pu}$. From $t=1.8 \mathrm{~s}$, these limits are gradually increased to $1 \mathrm{pu}$.

Both active and reactive currents are shared adequately between the different wind turbines.

The effects of the filter reduction on the reactive power delivered by the wind farm and the overall harmonic contents can be easily evaluated by comparing Figs. 4 and 5 . The connection transient is relatively fast, therefore, bank switching has not been considered.

Clearly, the current traces show a large ripple due to the increased harmonic contents when using the reduced capacitor bank. Otherwise, voltages, HVDC current and wind farm active power show similar behavior in both cases.

On the other hand, the reactive currents delivered by the wind farm $I_{W q i}$ show marked differences. In the original 


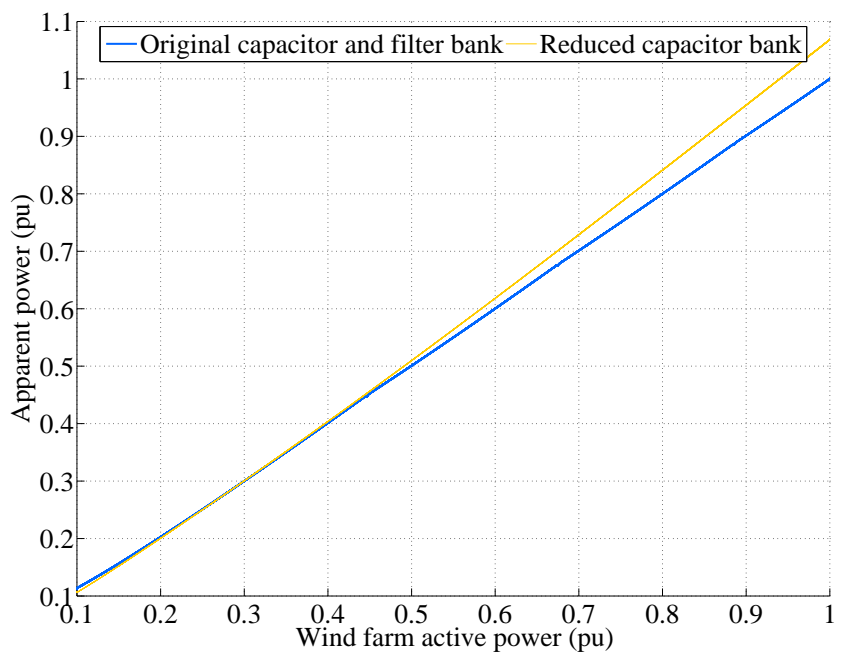

Fig. 6. Wind farm apparent power.

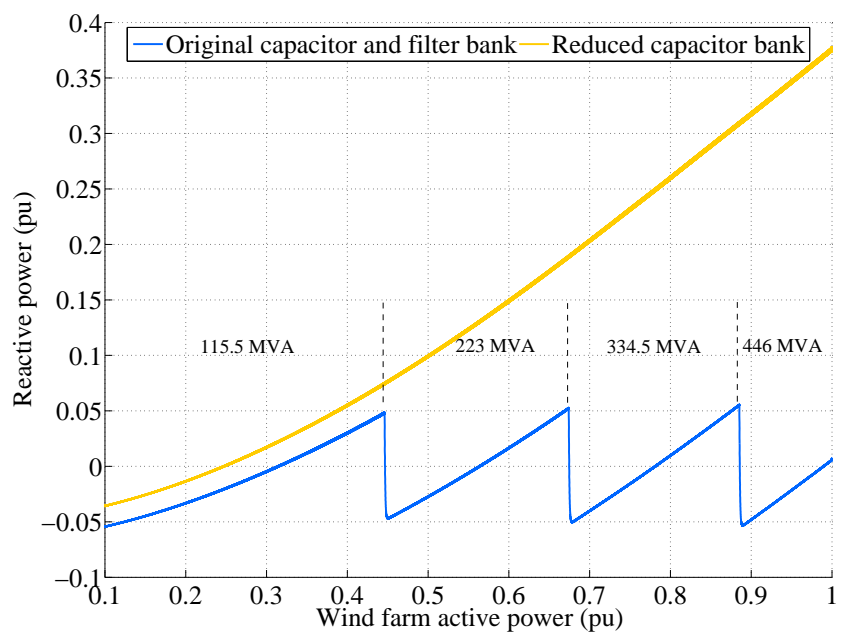

Fig. 7. Wind farm reactive power.

case, the wind farm does not deliver reactive current when generating rated power.

Conversely, with the reduced capacitor bank, the wind farm injects the reactive power previously provided by the harmonic filters.

As a result, the wind farm is required to produce 357 MVA reactive power at full load. Therefore, the wind turbine frontend converters and transformers must increase their power rating by around $6.5 \%$, as shown in Fig. 6.

During normal operation, the baseline capacitor and harmonic filter banks are switched on and off according to the HVDC link delivered power. Fig. 7 shows that, in this case, the wind farm reactive power is within a predefined limits of -0.05 to $0.05 \mathrm{pu}$.

In the reduced filter case, the wind farm must inject the reactive power not provided by the capacitor bank, which delivers 89 MVA independently of the HVDC link load. Therefore, at low loads, the HVDC rectifier is overcompensated and the wind farm needs to absorb reactive power. For generated power above $0.23 \mathrm{pu}$, the wind farm injects reactive power to a maximum of 357 MVA.

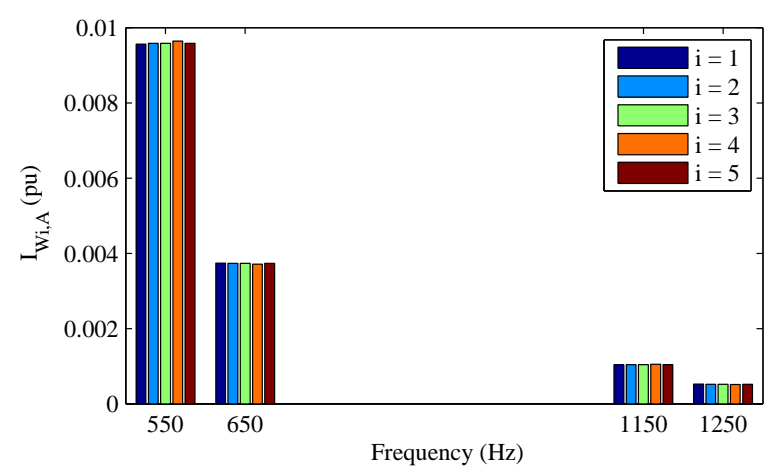

Fig. 8. Harmonic currents though each WT cluster with reduced filters.
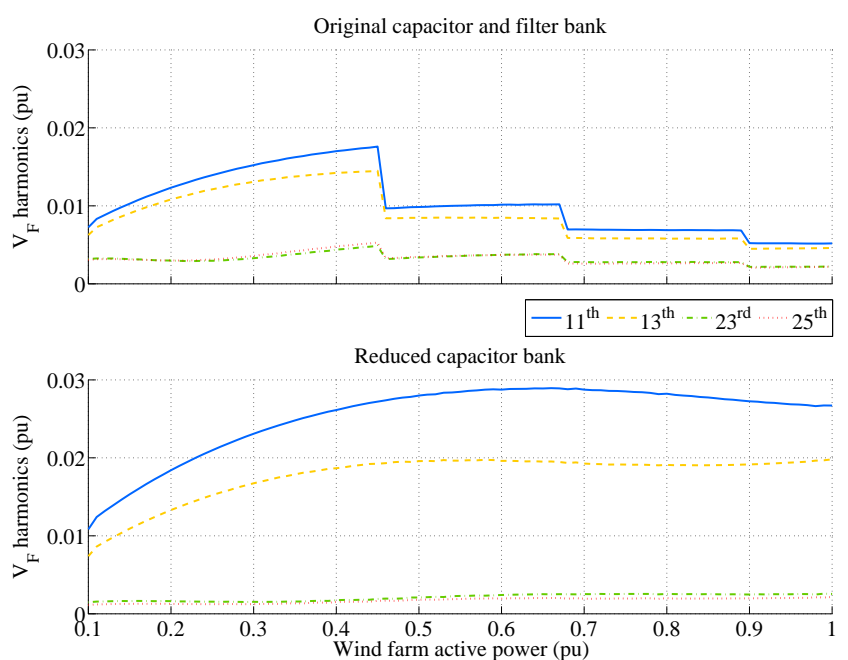

Fig. 9. Wind farm ac-grid voltage harmonics.

\section{A. Voltage and Current Distortion}

The effects of the filter and capacitor bank reduction on the harmonic contents of the off-shore ac-voltage $\left(V_{F}\right)$, the ac-side current of the diode rectifier $\left(I_{R}\right)$, the wind farm current $\left(I_{F}\right)$, and the capacitor bank current $\left(I_{C F}\right)$ are shown in Figs. 8 to 16 . In each case, the $11^{t h}, 13^{t h}, 23^{r d}$ and $25^{\text {th }}$ harmonics are presented as a ratio to the corresponding fundamental component.

Fig. 8 shows the amplitude of the $11^{t h}, 13^{t h}, 23^{r d}$ and $25^{\text {th }}$ current harmonics flowing through phase A of each WT cluster. Clearly, the harmonic contents are shared adequately amongst the different wind turbines.

The harmonic contents on the wind farm ac-grid voltage with original and reduced filter banks are shown in Fig. 9. The variation on the $23^{\text {rd }}$ and $25^{\text {th }}$ harmonics is almost negligible, while the $11^{\text {th }}$ and $13^{\text {th }}$ harmonics do increase.

However, neither of them are above $0.03 \mathrm{pu}$, which is the planning level stated in IEC-1000-3-6. These values correspond to a maximum total harmonic distortion of only $3.5 \%$, which is reached at half load and mantained thereafter, as shown in Fig. 10.

The distortion level of the wind farm ac-grid voltage is relatively small. Therefore, the harmonic contents of the HVDC rectifier ac-side current increase only marginally when 


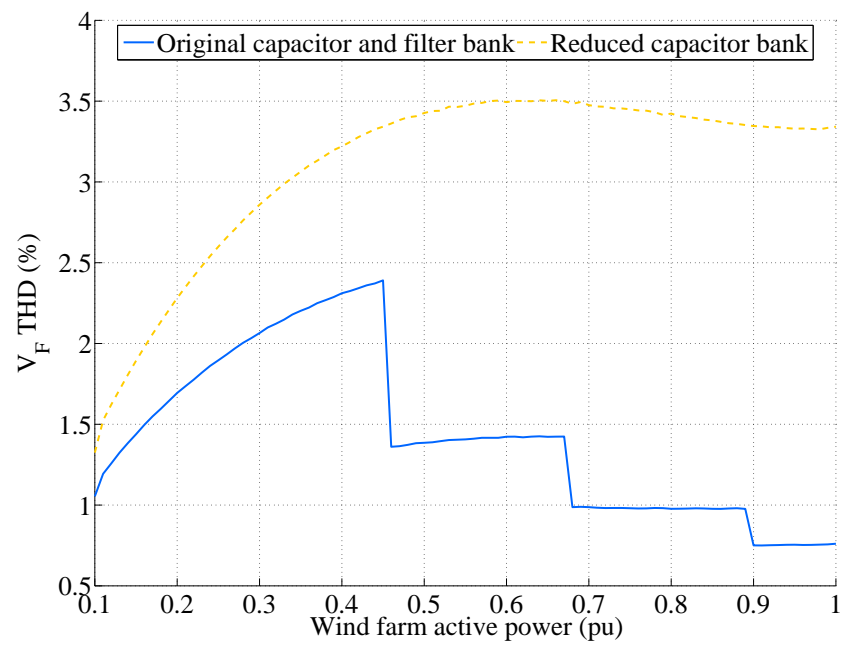

Fig. 10. Total harmonic distortion on ac-grid voltage.
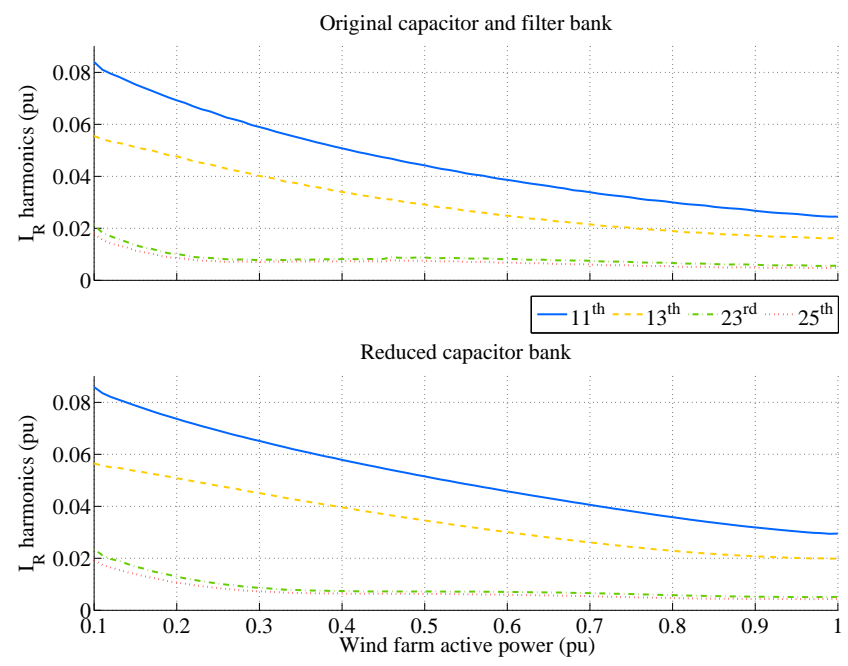

Fig. 11. HVDC diode rectifier ac-side current harmonics.

a reduced filter bank is used. Fig. 11 shows the small variation on the harmonic components of $I_{R}$ with the original and reduced banks. Hence, the $I_{R}$ total harmonic distortion (THD) shown in Fig. 12 are very similar in both cases.

The wind farm current harmonic contents are shown in Fig. 13. Note the $23^{r d}$ and $25^{t h}$ harmonics remain almost unchanged. However, as Fig. 13 clearly shows, the $11^{\text {th }}$ and $13^{\text {th }}$ harmonics substantially increase. Both have their maximum value at low load and decrease as load increases. In any case, the $11^{\text {th }}$ harmonic stays at or below $0.025 \mathrm{pu}$ and the $13^{\text {th }}$ harmonic is never above $0.013 \mathrm{pu}$.

As shown in Fig. 14, the harmonic contents of $I_{F}$ correspond to a total harmonic distortion up to $2.7 \%$ at low load and $1.2 \%$ at full load. Opposite to the behavior of $V_{F}$, the maximum distortion of both $I_{R}$ and $I_{F}$ takes place at minimum load and decreases as the load increases.

Finally, Fig. 15 shows that even voltage harmonics of a relatively small amplitude have an important effect on the currents through the capacitor bank. In both cases, at minimum load the $11^{\text {th }}$ harmonic is around $0.1 \mathrm{pu}$. The connection of the second bank in the baseline case produces a reduction in

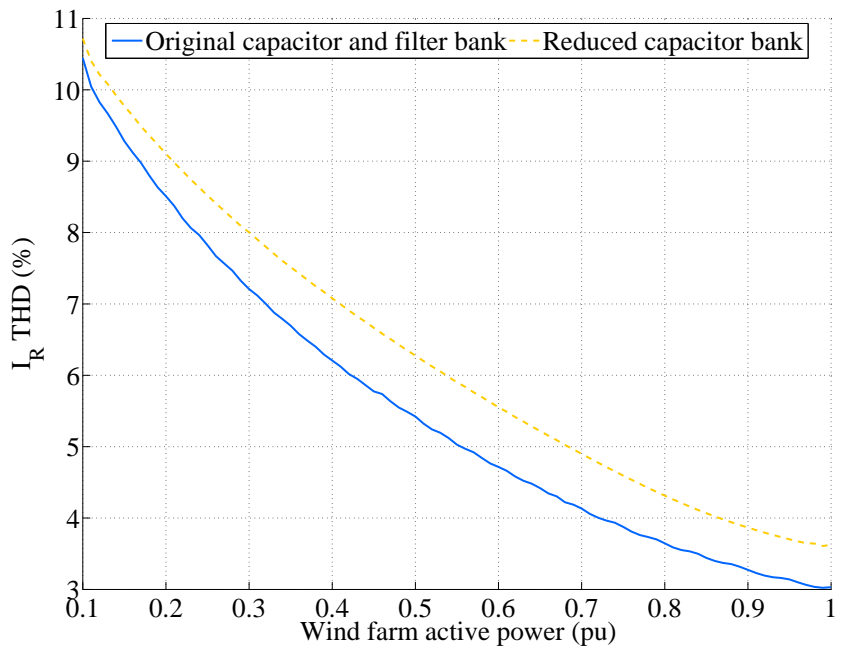

Fig. 12. Total harmonic distortion on diode rectifier ac-side current.
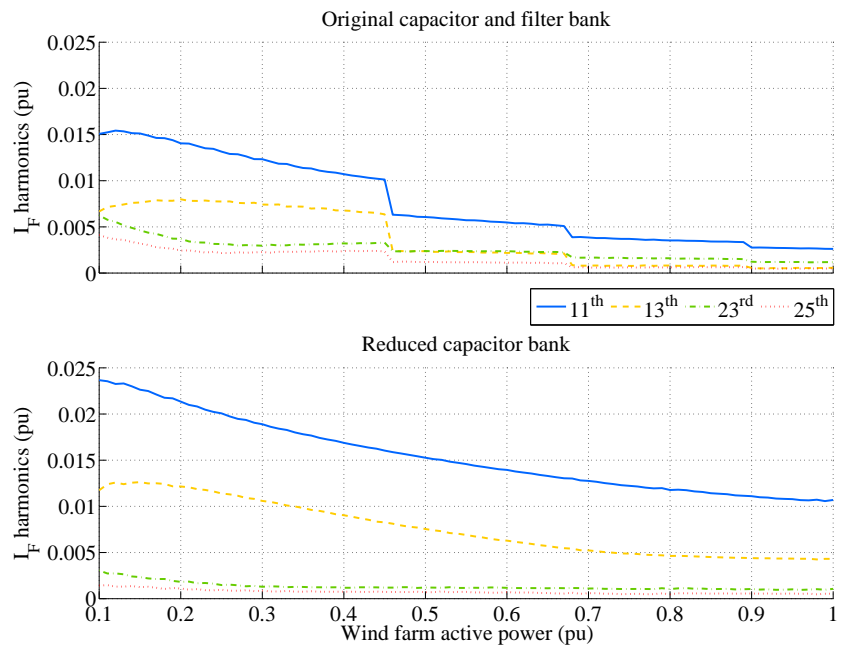

Fig. 13. Wind farm ac-grid current harmonics.

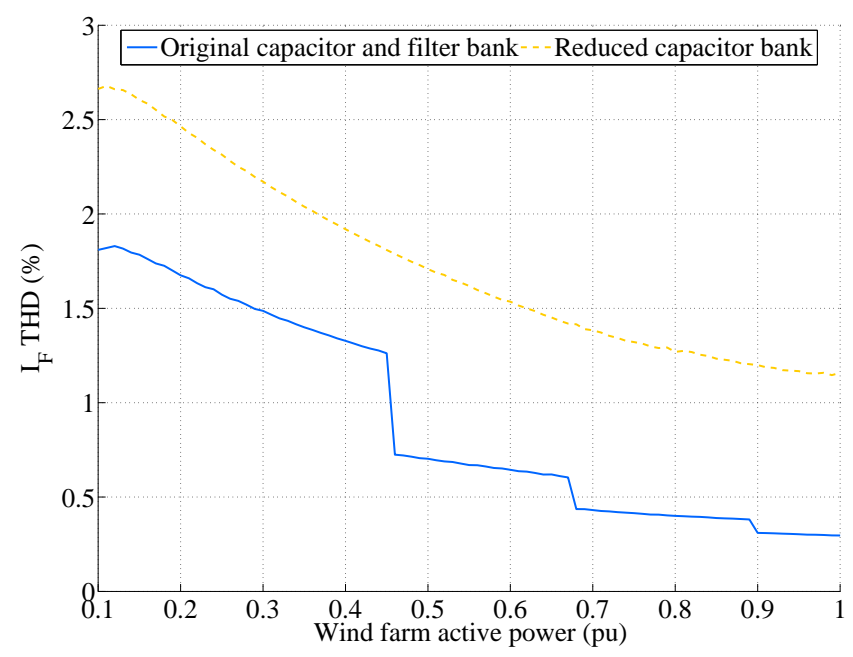

Fig. 14. Total harmonic distortion on wind farm ac-grid current. 

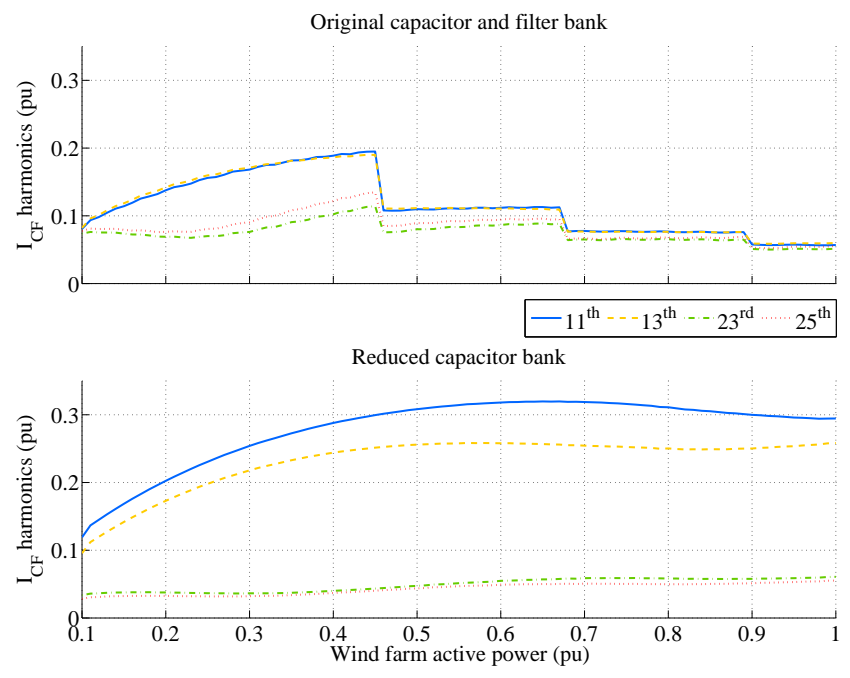

Fig. 15. Filter and capacitor bank current harmonics.

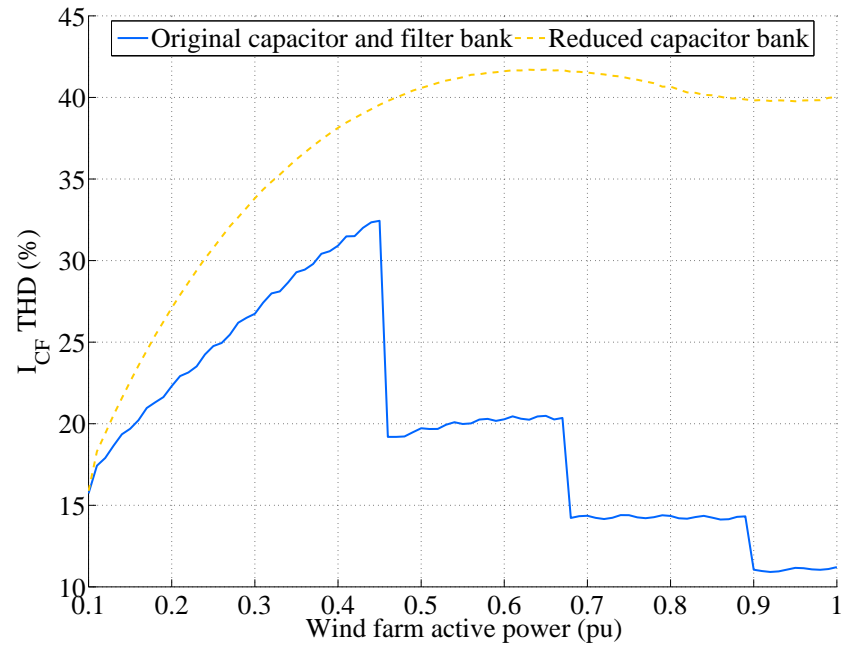

Fig. 16. Total harmonic distortion on filter and capacitor banks.

this harmonic. However, with the reduced capacitor bank, it continues raising to a maximum of $0.32 \mathrm{pu}$. This increase in harmonic contents has to be taken into account when defining the current rating of the capacitor bank.

Note the $I_{C F}$ THD, shown in Fig. 16, surpasses $40 \%$ for delivered power above $0.5 \mathrm{pu}$.

\section{B. Impact on Overall System Efficiency}

Even though the control system permits the operation of the wind farm with increased voltage and current harmonics, they would create additional losses in different parts of the system that must be taken into account. The main elements with increased losses are the different transformers, cables and wind turbine front-end converters. On the other hand, filter bank losses are reduced, as they are strongly dependent on its MVA rating.

1) Wind Turbine Transformer: Both copper and core losses of the wind turbine transformer will increase as the result of the increased harmonic and reactive currents delivered by the wind turbines [25].
A study on transformer harmonic losses is paramount to determine the derating of the wind turbine transformers. Transformer losses are divided into no-load losses and load losses. Manufacturers usually provide information about noload losses $\left(P_{N L L}\right)$ and load losses $\left(P_{L L}\right)$ at rated current [26]. No-load losses, also known as excitation losses, are mainly produced in the iron and have a value around $0.1 \%$. Voltage harmonic components increase this value since they affect hysteresis [27].

On the other hand, load-losses, also known as impedance losses, are mainly produced in the windings and, in multi megawatt transformers, have values around $1 \%$ at rated current. IEEE Std C57.110 [28] subdivides load losses into two parts: $I^{2} R$ losses and what is called "stray losses". The latter is the sum of the winding eddy-current losses $\left(P_{E C}\right)$ and other stray losses $\left(P_{O S L}\right)$. Therefore:

$$
P_{L L}=I^{2} R+P_{E C}+P_{O S L}
$$

Harmonic components affect all three terms of the load losses. $I^{2} R$ losses increase as the rms value of the transformer current increases. Moreover, a higher value of the resistance due to the skin effect can also be considered, especially with higher harmonic components.

Eddy-current losses vary with distorted currents according to an expression that is a function of its value under rated conditions $\left(P_{E C-R}\right)$ :

$$
P_{E C}=P_{E C-R} \sum_{h=1}^{h=h_{\max }}\left(\frac{I_{h}}{I_{n}}\right)^{2} h^{2}
$$

where $h$ is the harmonic order, $I_{h}$ is the rms current at harmonic $h$, and $I_{n}$ is the rms fundamental current under rated conditions.

The previous equation can be rewritten in per-unit quantities considering the rated current as the base current and $I^{2} R$ loss at rated current as the base losses, giving:

$$
P_{E C}(\mathrm{pu})=P_{E C-R}(\mathrm{pu}) \sum_{h=1}^{h=h_{\max }} I_{h}(\mathrm{pu})^{2} h^{2}
$$

Finally, similar expressions to (4) and (5) are suggested for other stray losses where the power of $h$ is changed by 0.8 . These losses are usually neglected for dry-type transformers, so they are not considered in this paper. Hysteresis loss is not considered either because no-load losses are far lower than load losses and, in our case, the transformer voltage shows a much smaller distortion than the current.

As a result, the loss increase due to eddy currents is calculated as an increment in the $I^{2} R$ and in $P_{E C}$ terms. The resistance of the wind turbine transformers is assumed to be $0.5 \%$, which corresponds to the value of $I^{2} R$ at rated current.

Moreover, load losses at rated current have been considered to be $P_{L L}=0.6 \%$ for each wind turbine transformer. Thus, $P_{E C-R}$ needed in (5) is only $0.1 \%$. These values are in agreement with [29].

In order to calculate the eddy-current losses of each turbine transformer, the four harmonic components of $I_{F}$ shown in Fig. 13 are introduced into (5). 
After calculation, the new value for the eddy-current losses at rated load is $0.106 \%$. This marginal increase with the reduced filter was expected according to the harmonics components of $I_{F}$ as $i$ ) the higher order components, which are multiplied by the order squared, are negligible; and $i i$ ) the distortion decreases as load increases, being significantly lower close to rated power.

Besides the increase in eddy current losses, the transformer copper losses would also increase, since now the wind turbines have to provide a large portion of the reactive power compensation required by the HVDC rectifier (Fig. 7). At low power, the reactive current delivered by the wind turbines is smaller than that of the base case. However, when the wind farm is delivering rated power, its current will be 1.06 times the base case current. Hence, rated power $I^{2} R$ losses would increase from $0.5 \%$ to $0.564 \%$ (i.e. $0.5 \times 1.06^{2}$ ).

Therefore, total transformer losses (eddy current plus $I^{2} R$ ) at rated power would increase from $0.6 \%$ to $0.67 \%$ when the reduced capacitor bank is used.

2) Capacitor and Filter Banks: Capacitor and filter bank losses are largely proportional to MVA bank rating. Therefore, the proposed filter reduction would lead to smaller capacitor and filter bank losses. A conservative figure for capacitor and filter bank losses would be $0.04 \%$, assuming $0.9 \%$ total HVDC rectifier station losses and $4.4 \%$ contribution of the capacitor and filter banks to total HVDC station losses [30].

Clearly, the power loss reduction would be dependent on the delivered active power, as the base case includes commutation of the capacitor and filter banks. At rated delivered power, the capacitor and filter bank losses will decrease from $0.04 \%$ to $0.008 \%$.

3) Wind Turbine Front-End Converter: Converter losses can be classified in switching and conduction losses. Moreover, for IGBT devices, conduction losses are further divided into losses proportional to $I$ and proportional to $I^{2}$ [31].

A detailed loss analysis should consider, at least, the converter topology, the particular device being used and the converter switching frequency. Typical figures for converter losses at rated load range from $1 \%$ to $2 \%$ [32], [33].

Therefore, a simplified loss calculation approach has been used here, whereby rated power front-end converter losses have been assumed to be $1.6 \%$ [32], [33] and proportional to the delivered current.

This simplifying assumption implies a small degree of loss overestimation at medium power, but otherwise reflects the behavior of IGBT front-end converter losses [32].

With this approach, the full power front-end converter losses are estimated to increase from $1.6 \%$ to $1.86 \%$ when the reduced capacitor bank is used.

Fig. 17 includes the total loss of the systems under consideration, namely wind turbine front-end converter and transformer, capacitor and filter banks. At full load, the reduced bank case leads to the increase of total losses from $2.265 \%$ to $2.41 \%$.

From Fig. 17, the annual losses for the considered systems can be calculated with the help of the Weibull distribution of specific sites. Three locations in the North Sea have been considered. Scale parameter $A$ and shape parameter $k$ for
TABLE I

ANNUAL LOSSES

\begin{tabular}{lcccc}
\hline Location & $A$ & $k$ & base case losses & reduced filter losses \\
\hline 1 & $9.8 \mathrm{~m} / \mathrm{s}$ & 2.1 & $1.74 \%$ & $1.83 \%$ \\
\hline 2 & $11.1 \mathrm{~m} / \mathrm{s}$ & 2.1 & $1.86 \%$ & $1.96 \%$ \\
\hline 3 & $7.2 \mathrm{~m} / \mathrm{s}$ & 2.1 & $1.31 \%$ & $1.36 \%$ \\
\hline
\end{tabular}

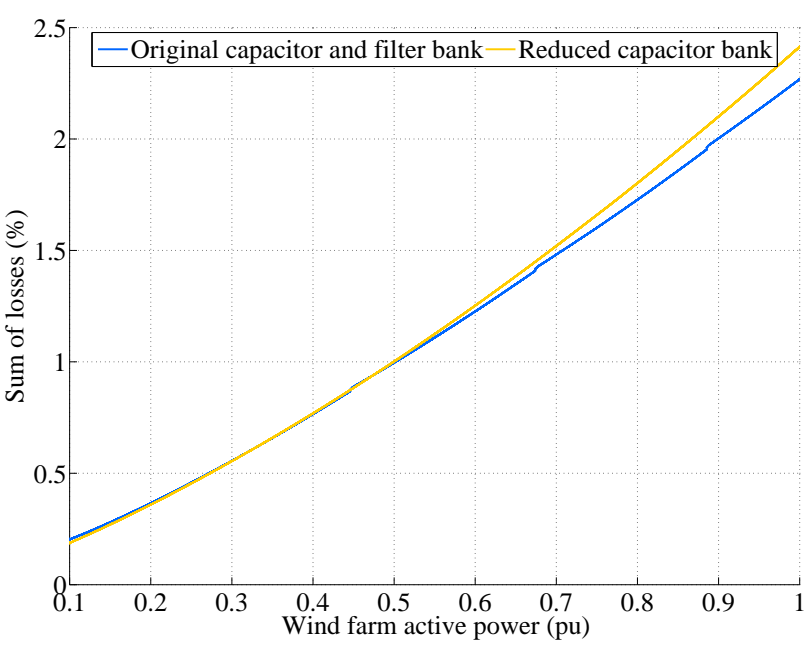

Fig. 17. Sum of losses in front-end converter, filter bank and WT transformer.

locations 1 and 2 are provided in [34], whereas for location 3, which corresponds to Horns Rev, is provided in [35]. The results are shown in Table I.

For the system elements under consideration, Fig. 18 shows the relative increase on the total losses as percentage of base case losses.

At low power, the wind turbine reactive current absorption is smaller in the reduced bank case. Moreover, capacitor bank losses are always smaller with the reduced capacitor bank. Therefore, there is $7.8 \%$ loss reduction at low power.

For generated power up to $0.5 \mathrm{pu}$, the filter reduction effect on the losses is either beneficial or negligible.

For power from 0.5 pu upwards, the use of the reduced filter implies an increase on existing losses, reaching a maximum of

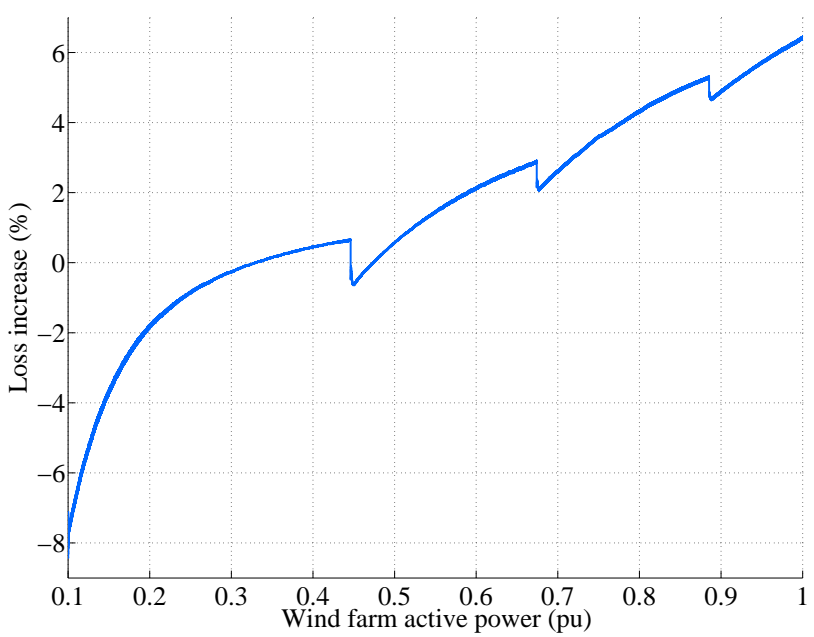

Fig. 18. Loss increase in front-end converter, filter bank and WT transformer. 
$6.4 \%$ at rated power. In the three considered locations, these values correspond to an increase of $5.3 \%$ in location 1, 5.6\% in location 2 , and $4.2 \%$ in location 3 .

\section{Discussion AND CONCLUSIONS}

This paper has shown that the control strategy introduced in [4] can be used with little modification when the rectifier harmonic filter and capacitor banks are reduced to one fifth of their original value. Moreover, it has been shown that the WPP is capable of energizing the HVDC link without the need of additional DC equipment.

The wind turbine front-end converters act as a distributed filter to absorb a large portion of the harmonic currents injected by the HVDC rectifier and to provide reactive power compensation.

The harmonic distortion on the off-shore ac grid voltage has been analyzed, as well as that of the different currents through the system. It has been found that the change on the harmonic currents injected by the HVDC rectifier is negligible.

On the other hand, the total harmonic distortion of the offshore ac grid voltage increases noticeably to a maximum value of 3.5\%, below the planning level stated in IEC-1000-3-6.

The wind turbine transformers and front-end converters need to be overrated by $6.5 \%$ to meet the increased reactive power requirements of the complete system at full load.

This is clearly a drawback of the proposed reduced filter solution, which should be weighed against its advantages, namely, reduced filter size and no need for filter bank switching (reduced cost and increased reliability) and the possibility of off-shore use of otherwise too large LCC rectifier stations, which are cheaper and more efficient than VSCHVDC stations. It has been shown that the increase on the WT transformer load losses due to the higher harmonic contents in wind turbine voltage and currents is negligible.

The fundamental and harmonic currents flowing through the HVDC rectifier are approximately equal in both the original and the reduced filter case. Therefore, the HVDC station does not need to be overrated.

Finally, a conservative efficiency study has lead to the conclusion that wind turbine transformer, front-end converter and filter bank losses would only increase by $6.4 \%$ at full power. Moreover, at powers below 0.5 pu the loss increment is very small, leading to loss reduction for powers below $0.35 \mathrm{pu}$.

Site specific studies have been carried out in order to calculate realistic loss increases in the aforementioned equipment. Calculated loss increase ranged from $4.3 \%$ to $5.6 \%$.

Therefore, the results presented in this paper show that the proposed control algorithm allows for the use a diode rectifier HVDC link with reduced filtering requirements and with small impact on overall system losses.

The results also show a good sharing of harmonic and reactive currents among the wind turbine front-end converters.

In any case, the reduction on the capacitor bank, together with the elimination of the need for switching filter banks, would lead to reduced installation costs and increased reliability, with a reduced impact on overall losses.

\section{APPENDIX}

\section{SYSTEM PARAMETERS}

\section{Off-Shore AC Grid:}

Base Values: $193.6 \mathrm{kV}$ L-N rms, $1.745 \mathrm{kA} \mathrm{rms,} 50 \mathrm{~Hz}$

\section{HVDC Link:}

Base Values: $500 \mathrm{kV}, 1000 \mathrm{MW}, 50 \mathrm{~Hz}$

Transformer $\mathrm{T}_{R}$ : 603.73 MVA, $50 \mathrm{~Hz}, 345 / 213 \mathrm{kV}$ (L-L rms), $X_{L}=0.18 \mathrm{pu}$.

HVDC Link Impedances: $R_{R}=R_{I}=2.5 \Omega, L_{R}=L_{I}=$ $0.5968 \mathrm{H}, C_{L}=26 \mu \mathrm{F}$.

Original filter and reactive power compensation bank (according to CIGRE benchmark):

$C_{F}=2.5181 \mu \mathrm{F}$

$Z_{F}$ (Low Frequency Filter):

$C_{a 1}=5.0369 \mu \mathrm{F}, C_{a 2}=55.9667 \mu \mathrm{F}, R_{a 1}=39.498 \Omega$, $R_{a 2}=347.5584 \Omega, L_{a}=181.0324 \mathrm{mH}$.

$Z_{F}$ (High Frequency Filter):

$C_{b}=5.0369 \mu \mathrm{F}, R_{b}=110.5837 \Omega, L_{b}=18.0502 \mathrm{mH}$.

Reduced capacitor bank:

$C_{F}=2.5181 \mu \mathrm{F}$

Controllers

PI Current Controllers: $K_{P}=33.83, K_{I}=28.188$

PI Voltage Controller: $K_{P}=583.8 \times 10^{-6}, K_{I}=0.048$

\section{REFERENCES}

[1] M. Liserre, R. Cárdenas, M. Molinas, and J. Rodríguez, "Overview of multi-MW wind turbines and wind parks," IEEE Transactions on Industrial Electronics, vol. 58, no. 4, pp. 1081-1095, Apr. 2011.

[2] R. Blasco-Gimenez, S. Añó Villalba, J. Rodríguez-D’Derlée, S. BernalPérez, and F. Morant, "Connection of large off-shore wind farms using diode based HVDC links," in Wind Energy Conversion Systems. Technology and trends. London: Springer-Verlag, 2012.

[3] R. Blasco-Gimenez, S. Añó Villalba, J. Rodríguez-D’Derlée, S. BernalPerez, and F. Morant, "Diode-based HVdc link for the connection of large offshore wind farms," Energy Conversion, IEEE Transactions on, vol. 26, no. 2, pp. $615-626$, Jun. 2011.

[4] R. Blasco-Gimenez, S. Añó Villalba, J. Rodríguez-D’Derlée, F. Morant, and S. Bernal-Perez, "Distributed voltage and frequency control of offshore wind farms connected with a diode-based HVdc link," Power Electronics, IEEE Transactions on, vol. 25, no. 12, pp. 3095-3105, 2010.

[5] S. Nishikata and F. Tatsuta, "A new interconnecting method for wind Turbine/Generators in a wind farm and basic performances of the integrated system," IEEE Transactions on Industrial Electronics, vol. 57, no. 2, pp. 468-475, Feb. 2010.

[6] T. Machida, I. Ishikawa, E. Okada, and E. Karasawa, "Control and protection of HVDC systems with diode valve converter," Name: Electr. Eng. Jpn.(Engl. Transl, 1978.

[7] J. Bowles, "Multiterminal HVDC transmission systems incorporating diode rectifier stations," Power Apparatus and Systems, IEEE Transactions on, vol. PAS-100, no. 4, pp. 1674-1678, 1981.

[8] S. Hungsasutra and R. Mathur, "Unit connected generator with diode valve rectifier scheme," IEEE Transactions on Power Systems, vol. 4, no. 2, pp. 538-543, May 1989.

[9] T. Kawaguchi, T. Sakazaki, T. Isobe, and R. Shimada, "Offshore windfarm configuration using diode rectifier with MERS in current link topology," Industrial Electronics, IEEE Transactions on, 2012, to be published.

[10] L. P. Lazaridis, "Economic comparison of HVAC and HVDC solutions for large offshore wind farms under special consideration of reliability," Master, Royal Institute of Technology Stockholm, 2005.

[11] N. Kirby, L. Xu, M. Luckett, and W. Siepmann, "HVDC transmission for large offshore wind farms," Power Engineering Journal, vol. 16, no. 3, pp. 135-141, 2002.

[12] M. Montilla-DJesus, D. Santos-Martin, S. Arnaltes, and E. Castronuovo, "Optimal operation of offshore wind farms with line-commutated HVDC link connection," Energy Conversion, IEEE Transactions on, vol. 25, no. 2 , pp. 504-513, 2010. 
[13] S. Kouro, M. Malinowski, K. Gopakumar, J. Pou, L. Franquelo, B. Wu, J. Rodriguez, M. Perez, and J. Leon, "Recent advances and industrial applications of multilevel converters," Industrial Electronics, IEEE Transactions on, vol. 57, no. 8, pp. 2553 -2580, Aug. 2010.

[14] L. Harnefors, A. Antonopoulos, S. Norrga, L. Angquist, and H. Nee, "Dynamic analysis of modular multilevel converters," Industrial Electronics, IEEE Transactions on, 2012, to be published.

[15] E. Solas, G. Abad, J. Barrena, S. Aurtenetxea, A. Carcar, and L. Zajac, "Modular multilevel converter with different subomodule concepts part II: Experimental validation and comparison for HVDC application," Industrial Electronics, IEEE Transactions on, 2012, to be published.

[16] N. Flourentzou, V. Agelidis, and G. Demetriades, "VSC-Based HVDC power transmission systems: An overview," Power Electronics, IEEE Transactions on, vol. 24, no. 3, pp. 592 -602, Mar. 2009.

[17] J. Napoles, J. Leon, R. Portillo, L. Franquelo, and M. Aguirre, "Selective harmonic mitigation technique for high-power converters," Industrial Electronics, IEEE Transactions on, vol. 57, no. 7, pp. 2315 -2323, july 2010.

[18] Y. Li, L. Luo, C. Rehtanz, C. Wang, and S. Ruberg, "Simulation of the electromagnetic response characteristic of an inductively filtered HVDC converter transformer using field-circuit coupling," Industrial Electronics, IEEE Transactions on, vol. 59, no. 11, pp. $4020-4031$, Nov. 2012.

[19] B. R. Andersen and L. Xu, "Hybrid HVDC system for power transmission to island networks," IEEE Transactions on Power Delivery, vol. 19, no. 4, pp. 1884-1890, Oct. 2004.

[20] Z. Xu, R. Li, H. Zhu, D. Xu, and C. Zhang, "Control of parallel multiple converters for direct-drive permanent-magnet wind power generation systems," IEEE Transactions on Power Electronics, vol. 27, no. 3, pp. 1259 -1270, Mar. 2012.

[21] S. Zhang, K.-J. Tseng, D. Vilathgamuwa, T. Nguyen, and X.-Y. Wang, "Design of a robust grid interface system for PMSG-Based wind turbine generators," IEEE Transactions on Industrial Electronics, vol. 58, no. 1, pp. $316-328$, Jan. 2011.

[22] M. Szechtman, T. Wess, and C. V. Thio, "First benchmark model for HVDC control studies," Electra, vol. 135, no. 4, pp. 54-67, 1991.

[23] R. Cárdenas, R. Peña, G. M. Asher, J. Clare, and R. Blasco-Gimenez, "Control strategies for power smoothing using a flywheel driven by a sensorless vector-controlled induction machine operating in a wide speed range," Industrial Electronics, IEEE Transactions on, vol. 51, no. 3, pp. 603-614, 2004.

[24] R. Peña, J. Clare, and G. Asher, "A doubly fed induction generator using back-to-back PWM converters supplying an isolated load from a variable speed wind turbine," Electric Power Applications, IEE Proceedings -, vol. 143, no. 5, pp. 380-387, 1996.

[25] T. Kefalas and A. Kladas, "Analysis of transformers working under heavily saturated conditions in grid-connected renewable-energy systems," Industrial Electronics, IEEE Transactions on, vol. 59, no. 5, pp. 2342 -2350 , may 2012.

[26] ABB, "Technical data ecodry dry-type transformers." [Online]. Available: www.abb.com

[27] T. D. Kefalas and A. G. Kladas, "Harmonic impact on distribution transformer no-load loss," Industrial Electronics, IEEE Transactions on, vol. 57, no. 1, pp. 193-200, 2010.

[28] "IEEE recommended practice for establishing liquid-filled and dry-type power and distribution transformer capability when supplying nonsinusoidal load currents - Redline," IEEE Std C57.110-2008 (Revision of IEEE Std C57.110-1998) - Redline, pp. 1-67, 2008.

[29] L. Pei, L. Guodong, X. Yonghai, and Y. Shujun, "Methods comparation and simulation of transformer harmonic losses," in Power and Energy Engineering Conference (APPEEC), 2010 Asia-Pacific, 2010, pp. 1-4.

[30] "IEEE recommended practice for determination of power losses in highvoltage direct-current (HVDC) converter stations," IEEE Std 1158-1991, pp. 1-53, 1992.

[31] A. Garcés and M. Molinas, "A study of efficiency in a reduced matrix converter for offshore wind farms," IEEE Transactions on Industrial Electronics, vol. 59, no. 1, pp. 184-193, Jan. 2012.

[32] L. Helle and S. Munk-Nielsen, "Comparison of converter efficiency in large variable speed wind turbines," in Sixteenth Annual IEEE Applied Power Electronics Conference and Exposition, 2001. APEC 2001, vol. 1. IEEE, 2001, pp. 628-634 vol.1.

[33] H. Zhang and L. M. Tolbert, "Efficiency impact of silicon carbide power electronics for modern wind turbine full scale frequency converter," IEEE Transactions on Industrial Electronics, vol. 58, no. 1, pp. 21-28, Jan. 2011
[34] J. Coelingh, A. van Wijk, and A. Holtslag, "Analysis of wind speed observations over the North Sea," Journal of Wind Engineering and Industrial Aerodynamics, vol. 61, no. 1, pp. 51-69, Jun. 1996.

[35] C. B. Hasager, R. J. Barthelmie, M. B. Christiansen, M. Nielsen, and S. C. Pryor, "Quantifying offshore wind resources from satellite wind maps: study area the North Sea," Wind Energy, vol. 9, no. 1-2, pp. 63-74, 2006.

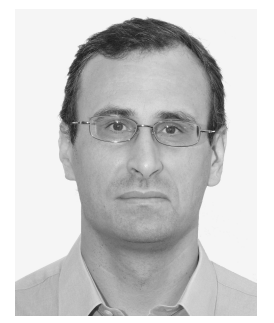

Ramon Blasco-Gimenez (S'94-M'96-SM'10) obtained his BEng degree in Electrical Engineering from the Universitat Politècnica de València (Spain) in 1992 and his PhD degree in Electrical and Electronic Engineering from the University of Nottingham (UK) in 1996. From 1992 to 1995 he was a Research Assistant at the Dept. of Electrical and Electronic Engineering of the University of Nottingham. In 1996 he joined the Dept. of Systems Engineering and Control of the Universitat Politècnica de València, where he is currently an Associate Professor. His research interests include Control of Motor Drives, Wind Power Generation and Grid Integration of Renewable Energy Systems. Dr BlascoGimenez has been a co-recipient of the 2005 IEEE Transactions on Industrial Electronics Best Paper Award. Dr Blasco-Gimenez is a registered professional engineer in Spain, a Chartered Engineer in the U.K. and a member of the Institute of Engineering and Technology.

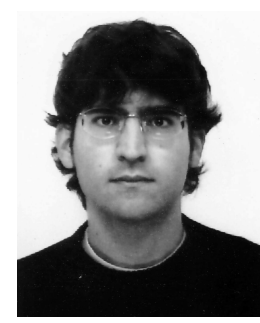

Néstor Aparicio (S'06-M'12) received the M.Sc. degree from the Universitat Jaume I (UJI), Castelló de la Plana, Spain, in 2002, and the Ph.D. degree from Universitat Politècnica de València (UPV), Spain, in 2011. He is an Assistant Professor of the Electrical Engineering Area at UJI with research interests in the grid integration of wind-power generators. For 6 months, he visited the Institute of Energy Technology of Aalborg, Denmark and the Centre for Energy and Environmental Markets (CEEM), Sydney, Australia in 2006 and 2008, respectively.

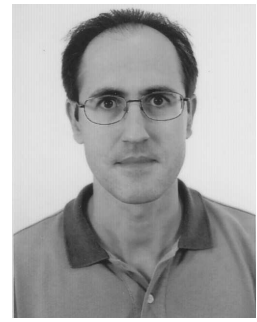

Salvador Añó-Villalba received his M.Sc. and $\mathrm{Ph} . \mathrm{D}$. degrees in Electrical Engineering from the Universitat Politècnica de València, in 1988 and 1996, respectively. From 1987 to 1989 he worked for the R\&D Department of Electronic Traffic S.A. to develop hardware and software for street lighting measuring and automation. In 1988 he joined the Dept. of Electrical Engineering of the Universitat Politècnica de València, where he is currently an Associate Professor. His current research interests include wind energy and electrical machines.

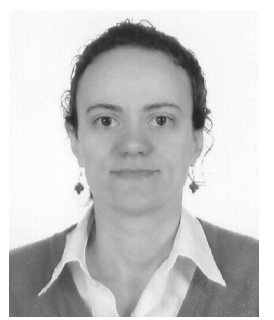

Soledad Bernal-Perez received her M.Sc. degree in electrical engineering from Universitat Politècnica de València, Spain, in 1999. From 2001 to 2012 she worked as Radio Engineer, carrying out surveys of Global Maritime Distress Safety Systems (GMDSS) radio installations on board of commercial ships for the main Classification Societies. Since 2003, she has been a lecturer at the Dept. of Electrical Engineering of the Universitat Politècnica de València, where she is currently working towards her Ph.D. degree. Her area of interest is grid integration of off-shore wind farms using HVDC links. 